\title{
SHIP RESISTANCE WHEN OPERATING IN FLOATING ICE FLOES: A DERIVATION OF EMPIRICAL EQUATIONS
}

\author{
Luofeng Huang ${ }^{1}$, Christopher Ryan, Bojan Igrec, \\ Andrea Grech La Rosa, Dimitris Stagonas², \\ Giles Thomas \\ University College London \\ London, United Kingdom
}

\author{
Zhiyuan Li, Minghao $\mathrm{Li}^{3}$, Jonas W. Ringsberg \\ Chalmers University of Technology \\ Gothenburg, Sweden
}

\begin{abstract}
With the effects of global warming, the Arctic is presenting a new environment where numerous ice floes are floating on the open sea surface. Whilst this has unprecedentedly improved Arctic shipping navigability and brought about significant opportunities, the interaction of such floes with ships has yet to be understood, thus hindering appropriate assessment of corresponding ship performance. This paper presents work on developing empirical equations to estimate the effects of such floes on ship resistance. Based on extensive data from validated computational simulations, the ice-floe resistance has been shown to correlate with ship beam, ship speed, ice concentration, ice thickness and floe diameter, and the regression powers of each the parameter on resistance are ascertained for a container ship. This leads to an empirical equation that can immediately predict ice-floe resistance in a given condition. The proposed approach has the potential to facilitate propulsion power estimates for Arctic shipping, as well as providing valuable insights into ship design for these environmental conditions.
\end{abstract}

Keywords: Ice floe, Ship resistance, Empirical equation.

\section{INTRODUCTION}

Climate change has caused Arctic sea ice to melt dramatically, in turn causing an extensive transition from levelice coverage to broken ice-floe fields and open water [1]. The changing conditions make the Arctic more accessible to ships, with new waterways allowing improved access for oil and gas extraction, mining, fishing and tourism. In addition, there are two major cargo-shipping routes becoming viable: the Northwest Passage (NWP) and the Northern Sea Route (NSR), alternatives to the Panama and Suez canals to connect Europe, Asia and

1 Contact author: ucemlhu@ucl.ac.uk

${ }^{2}$ Now at: Cranfield University ${ }^{3}$ Now at: FS Dynamics
America. Compared with current routes, both new routes can reduce travel distance by up to $40 \%$, leading to substantial fuel, cost, time and emission savings [2].

There have been a significant number of complete transits via the emerging Arctic sea routes. In 2019 alone, 24 and 35 ships transited through the NWP and NSR respectively, and there were over 2000 cargo voyages completed via the NSR $[3,4]$. Multiple predictive models have indicated an ongoing increase in the scale of shipping through these routes [5]. These trends are attracting special research interests in Arctic shipping, one of which is to identify potential ice conditions and conduct corresponding ship design and power estimates.

Traditional polar ship design has focused on the level-ice condition, as the Arctic region tended to be covered by consolidated ice all year round and was only accessible to icebreakers. A large number of models were developed to formulate the ice-breaking process so as to predict the ice resistance on ships [6-8]. These models have been widely applied in practice and evolved into international guidelines, such as the Finnish-Swedish Ice Class Rules [9].

However, completed voyages in the Arctic have reported very different conditions from the traditional level-ice. The emerging shipping routes are observed to be dominated by broken ice floes, especially during the summer season [1]. The floating floes can be of a range of sizes, and the water surface is only partly covered by ice. In addition, those floes tend to be circular under the effect of wave wash and floe-floe collisions, thus known as pancake ice, as shown in Figure 1. Despite certain level ice can still be encountered then ice-breaker assistance would be needed [10], such ice-floe conditions are navigable for commercial ships designed for open water, thus it has become an important future scenario for Arctic shipping. 
The process of a ship advancing in floating ice floes can be summarised as the following ship-wave-ice interaction: ship advancement generates waves; waves interact with ice floes; ice floes make contact with each other and with the ship. In this scenario, sailing ships tend to push the floes aside rather than break them [11], which means that the mechanism of ice resistance on the ship is different from in level ice. In other words, existing resistance predictions for the level-ice condition may not be applicable for the new Arctic shipping condition. For ship resistance in broken ice floes, Guo et al. [12], Luo et al. [13] and Kim et al [14] conducted model tests to acquire data. Woolgar and Colbourne [15] presented regression analyses based on experimental data to derive the relationship of ice-floe load on a moored vessel with ice drift speed, ice friction, floe size and ice concentration; however, as their tests were conducted to study ice loads on a moored structure, the examined ice speed conditions are very small compared with normal shipping speeds, thus those relationships cannot be directly applied to ship resistance in ice floes, since ship-generated waves were negligible in their scenario. On the whole, related research in floe ice is still very scarce, partially because the topic is new rising, also due to the prohibitive costs and complexity of ice experiments involving parameter matrices.

In such a context, Huang et al. $[16,17]$ developed a highfidelity computational model using a combined CFD \& DEM (Computational Fluid Dynamics and Discrete Element Method) approach that is able to simulate the operation of a ship in floating ice floes, as shown in Appendix Figure I-II. This approach benefits from CFD that can obtain fully nonlinear fluid solutions, as well as DEM that can solve solid contacts, and experiments have confirmed the accuracy of this approach in predicting the ice-floe resistance. Moreover, ship and ice parameters such as hull form, ship speed and ice dimensions can be easily changed, thus allowing the consideration of extensive input combinations.

Despite the affordability of computational simulation, it may be impractical to run a simulation each time a power estimate is needed. Therefore, there is the need to develop empirical equations for the immediate estimation of ice resistance for a given condition. One particular example is the Arctic Voyage Planning Tool (VPT). The VPT, with the purpose of improving the safety and efficiency of cargo vessels operating in the Arctic, is designed as planning and optimisation of the routes in ice-infested waters, as developed by Li et al. $[18,19]$. Such VPTs especially need a real-time estimate of ice resistance for each potential route to provide decision-making support for the crew.

For this purpose, this paper presents a subsequent work based on the approach of Huang et al. [17]. In the remainder of this paper, simulation results with varying input parameters will be presented followed by the derivation of an empirical equation of ice-floe resistance $\left(R_{\text {ice}}\right)$ for a container ship. Particularly, a non-dimensional derivation process will be presented, which can be easily applied to other candidate ships. The extrapolation from model-scale ice resistance to full-scale will also be discussed.

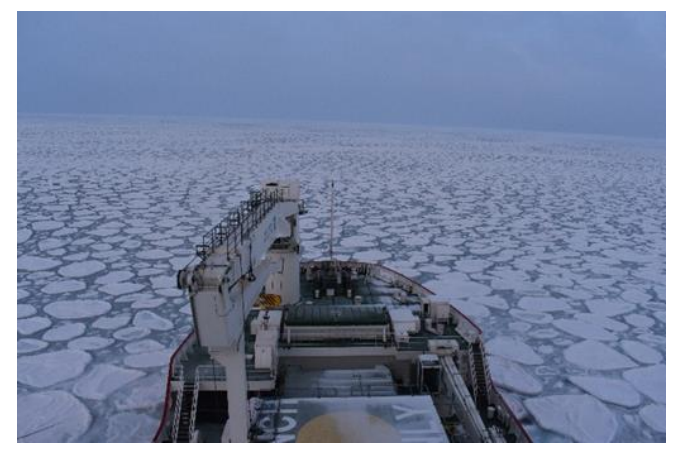

FIGURE 1: A ship advancing in floating ice floes (photo credit: Alessandro Toffoli).

\section{PRINCIPAL PARAMETERS}

A modern container ship model, KRISO Container Ship (KCS), was adopted as the candidate ship for this study. KCS is a typical container ship model employed in the field of numerical simulations, and there are experimental data of water resistance and ice-floe resistance available for validating computational models $[12,20]$. The hull parameters are summarised in Table 1 . Prior to this work, the approach of Huang et al. [17] has been proved accurate on predicting both water and ice resistance for $\mathrm{KCS}$, as presented in Figure 2.

The KCS hull is placed in the CFD \& DEM model [17] to simulate its advancement in pancake ice, in which: (a) a standard CFD model for ship advancement in open water is applied to obtain fluid solution, including the ship-generated wave; (b) DEM is used to model ice floes (assumed to be rigid disks) as well as their collisions with the ship and nearby floes [21], and those floes obtain fluid force from the CFD solution so that the ship-wave-ice coupling is achieved [22]; (c) floe-distribution algorithms were developed to enable the import of natural icefloe fields into the CFD \& DEM model, thus the floes are randomly distributed and of a range of sizes according to field measurements, as presented in Appendix Figure I-II.

Based on extensive simulations considering various environmental variables, the most influential parameters on $R_{\text {ice }}$ have been identified. They are ship beam, ship speed, ice concentration, ice thickness and floe size, as introduced in Table 2 . The relationship of $R_{\text {ice }}$ with these parameters was studied by running simulations while only varying a specific parameter with certain increments. An example is shown in Figure 3, by which the ship speed and ice concentration were examined in certain ranges to obtain their regression powers, turning out to be 1.2 and 1.5 respectively. Similarly, the relationships of $\mathrm{R}_{\text {ice }}$ with ship beam, ice thickness and floe size were found to be linear, as plotted in Figure 4-6.

The obtained powers of ship speed and floe size are very close to the results of Woolgar and Colbourne [15] (1.2 against 1 and 1 against 0.9$)$, and the power of ice concentration is slightly lower than that obtained by Guo et al. [12] (1.5 against 2). The power of ice thickness is studied for the first time for floe-ice, while the unit power of ice thickness has also been shown in level-ice and brash-ice conditions [7, 22]. The linear relationship 
of ship beam can be attributed to a changed contact surface between ship and ice, as the contacts mainly happen over the ship waterline. This makes ship beam an essential parameter and suggests relatively slender ship design may be more suitable for the ice-floe condition.

TABLE 1: Main dimensions of the KCS hull.

\begin{tabular}{|c||c||c|c|}
\hline Parameter & Symbol & Model scale & Full scale \\
\hline $\begin{array}{c}\text { Length between } \\
\text { perpendiculars (m) }\end{array}$ & $\mathrm{L}_{\mathrm{pp}}$ & 4.367 & 230.0 \\
\hline Waterline beam (m) & $\mathrm{B}$ & 0.611 & 32.2 \\
\hline Draught midships (m) & $\mathrm{T}$ & 0.205 & 10.8 \\
\hline Trim angle (rad) & $\mathrm{q}$ & 0.0 & 0.0 \\
\hline Block coefficient (-) & $\mathrm{CB}$ & 0.651 & 0.651 \\
\hline Wetted surface area (m $\left.{ }^{2}\right)$ & $\mathrm{Sw}$ & 3.435 & 8992.0 \\
\hline
\end{tabular}

TABLE 2: Essential variables for $\mathrm{R}_{\text {ice. }}$.

\begin{tabular}{|c||c|c|c|}
\hline Parameter & Definition & Symbol & [unit] \\
\hline Ship beam & $\begin{array}{c}\text { Maximal width on the } \\
\text { ship's design waterline }\end{array}$ & $\mathrm{B}$ & {$[\mathrm{m}]$} \\
\hline Ship speed & Straight-line speed & $\mathrm{V}$ & {$\left[\mathrm{m}^{*} \mathrm{~s}^{-1}\right]$} \\
\hline $\begin{array}{c}\text { Ice } \\
\text { concentration }\end{array}$ & $\begin{array}{c}\text { The proportion of a } \\
\text { certain sea surface } \\
\text { covered by ice }\end{array}$ & $\mathrm{C}$ & {$[-]$} \\
\hline Ice thickness & $\begin{array}{c}\text { The average thickness } \\
\text { of all floes }\end{array}$ & $h$ & {$[\mathrm{~m}]$} \\
\hline Aspect ratio & $\begin{array}{c}\text { The ratio of a floe's } \\
\text { diameter to its thickness }\end{array}$ & $\mathrm{AR}$ & {$[-]$} \\
\hline Ice density & $\begin{array}{c}\text { Assume its value for all } \\
\text { ice is } 900\end{array}$ & $\rho_{\text {ice }}$ & {$\left[\mathrm{kg}^{*} \mathrm{~m}^{-3}\right]$} \\
\hline
\end{tabular}

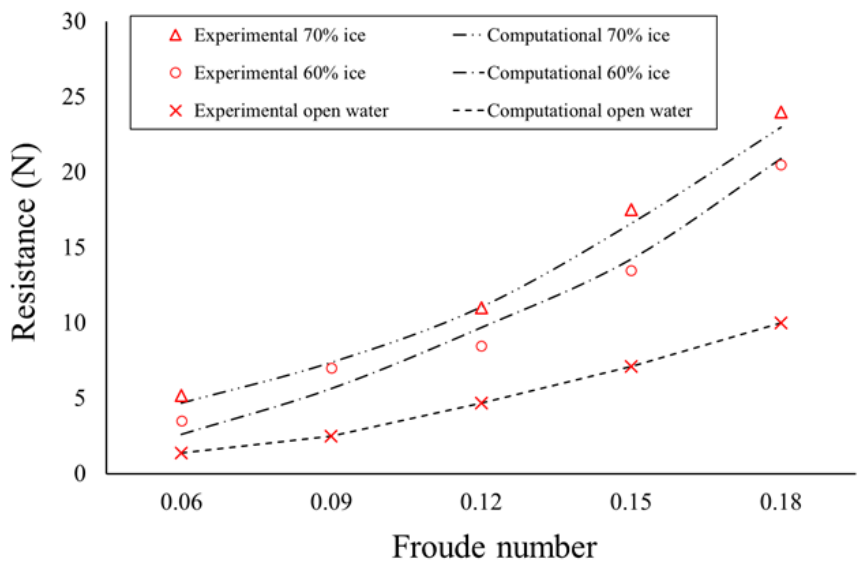

FIGURE 2: Experimental [12] and computational total resistance of model-scale KCS operating in ice concentration $60 \%$ and $70 \%$, alongside the water component.

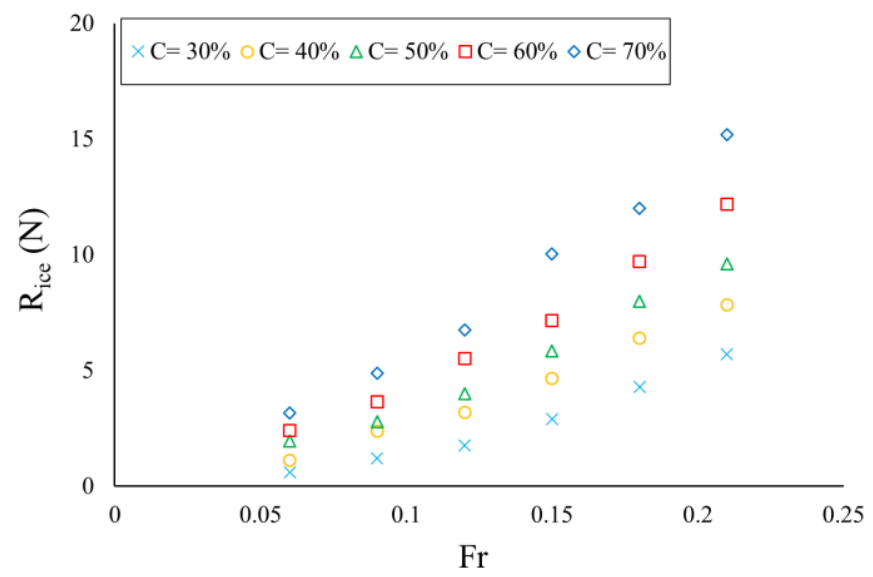

FIGURE 3: Ice-floe resistance in varying ice concentrations and ship speeds, obtained when $h=0.02 \mathrm{~m}$.

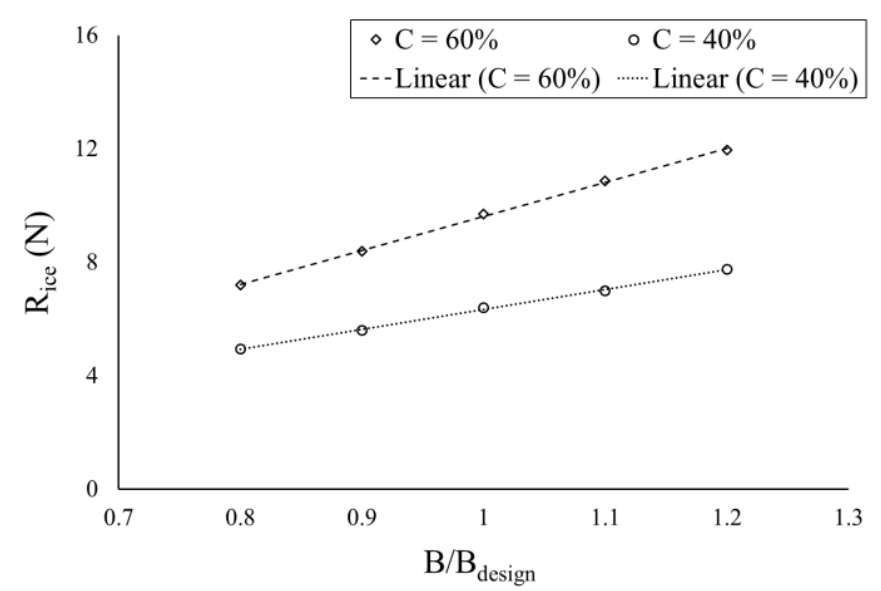

FIGURE 4: Ice-floe resistance as a function of ship beam (normalised by the design beam), obtained when $\mathrm{Fr}=0.18$ and $h$ $=0.02 \mathrm{~m}$.

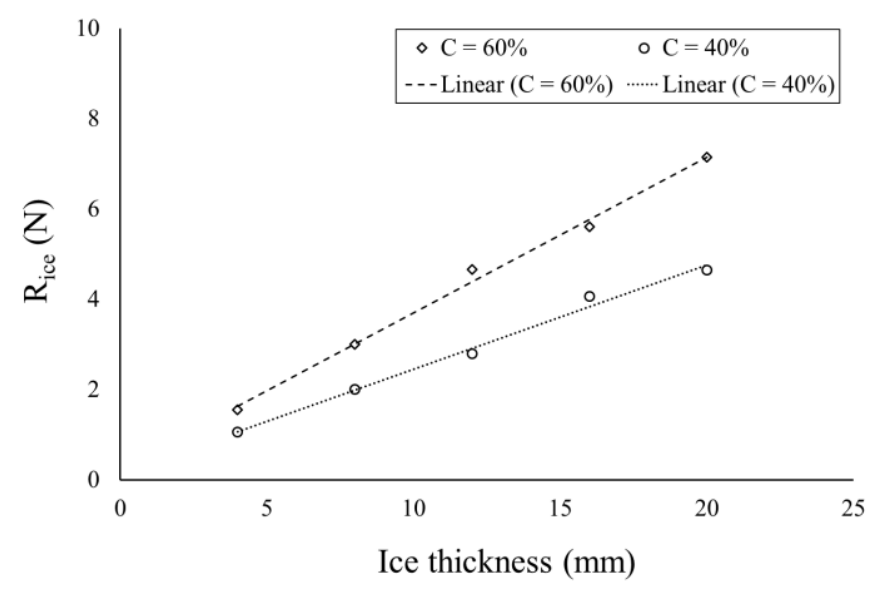

FIGURE 5: Ice-floe resistance in varying ice thickness, obtained when $\mathrm{Fr}=0.15$. 


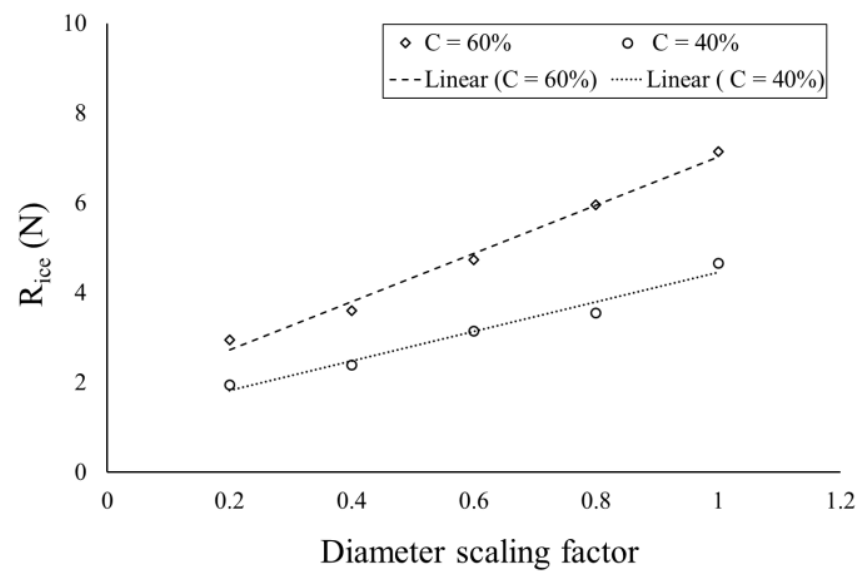

FIGURE 6: Ice-floe resistance as a function of floe size (floe diameters in [12] globally scaled by a factor), obtained when Fr $=0.15$ and $h=0.02 \mathrm{~m}$.

\section{EQUATION DERIVATION}

$\mathrm{R}_{\text {ice }}$ is first expressed using parameters shown in Table 2. This gives: $\quad R_{\text {ice }}=A \times \rho_{\text {ice }}^{a} \times B^{b} \times h^{c} \times V^{d} \times C^{m} \times$ $A R^{n}$, where $\mathrm{A}$ is a coefficient dependent on the specific ship. Subsequently, using a standard non-dimensional method to fit the units of both sides, it gives: $\mathrm{a}=1, \mathrm{~b}+\mathrm{c}=2$ and $\mathrm{d}=2$, thus,

$$
R_{\text {ice }}=A \times \rho_{\text {ice }} \times B^{b} \times h^{c} \times V^{2} \times C^{m} \times A R^{n}
$$

Based on the regression powers shown for $\mathrm{B}, h, \mathrm{C}$ and $\mathrm{AR}$, $\mathrm{b}=1, \mathrm{c}=1, \mathrm{~m}=1.5$ and $\mathrm{n}=1$. Since the power of speed was found to be 1.2, while its unit-based power is 2 , a nondimensional parameter Froude number $\left(\mathrm{Fr}=\mathrm{V} / \sqrt{g \times L_{p p}}\right)$ is introduced to fulfil both the power and unit; thereby the power of Fr derives to be -0.8 , thus:

$$
R_{\text {ice }}=A \times \rho_{\text {ice }} \times B \times h \times V^{2} \times C^{1.5} \times F r^{-0.8} \times A R
$$

As ice floes in a certain region are of different sizes, the AR of each floe can be different. Thus, an average AR of 10 is used according to field measurements [24]. This value of AR can merge into the coefficient A.

Afterwards, the KCS parameters are inserted and then A was found to be 0.17 . Thus, the derived equation for ice resistance in this case is as follows:

$$
R_{\text {ice }}=0.17 \times \rho_{\text {ice }} \times B \times h \times V^{2} \times C^{1.5} \times F^{-0.8}
$$

Equation (3) can provide relatively accurate predictions for ice resistance, as shown in Figure 7.

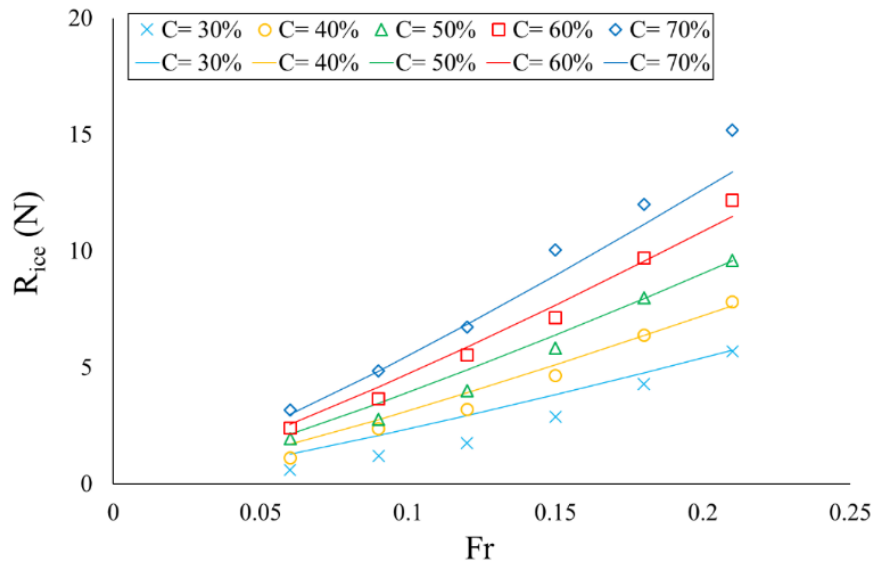

FIGURE 7: Ice-floe resistance calculated by simulations (dots) and Equation (3) (lines), for KCS hull at model scale, when $h=$ $0.02 \mathrm{~m}$.

\section{FULL-SCALE EXTRAPOLATION}

The computational modelling was conducted in model scale to allow validation against experiments, so it is of importance to discuss how the $R_{i c e}$ results can be applied to full scale. For ship resistance in open water $\left(\mathrm{R}_{\text {water }}\right)$, the derivation of formulae from model tests usually need to apply the ITTC extrapolation procedure [25], since it is impossible to ensure Froude and Reynolds numbers are equal in both full scale and model scale, in which, the former governs gravity/inertia (waves) forces and the latter dictates viscous forces. $\mathrm{R}_{\text {water }}$ can be divided into a wave component and a friction component; in model tests, scaling based on a consistent Froude number is practical, which scales the wave component correctly while brings about certain errors within the friction component due to a changed Reynolds number. The latter may be corrected using the ITTC method [25].

Similarly, for the extrapolation of ice resistance, Froude and Cauchy numbers shall be equal in both full scale and model scale [26]; the latter relates to the elasticity of ice, ensuring the elastic reaction forces of ice are correctly scaled, which is essential in accurately representing the ice-breaking process. However, in the present ice-floe case, in principle floating ice floes are pushed away rather than broken by the ship, so those floes can be assumed to be rigid [11], thus the Cauchy number is consistent and does not need relevant corrections. Therefore, the present work proposes that Equation (3) can be directly applied to full scale, as the non-dimensional derivation has already kept the expression in line with the Froude's law. An example of $\mathrm{R}_{\text {ice }}$ prediction in full scale is shown in Figure 8, which could be further examined by full-scale measurements/simulations in future work. 


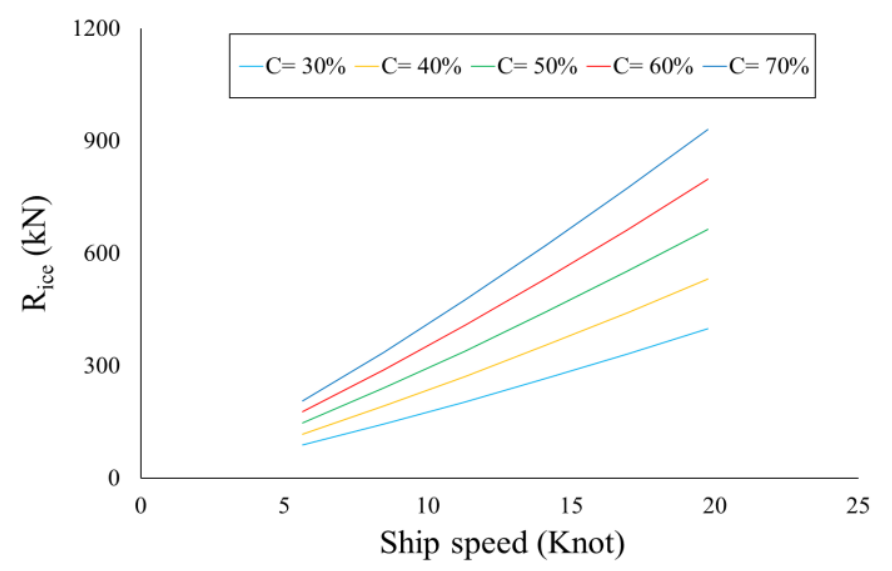

FIGURE 8: Ice-floe resistance predicted by the empirical equation, for KCS hull at full scale, when $h=0.5 \mathrm{~m}$.

\section{CONCLUSIONS}

The reduction in sea ice has resulted in increased navigability for commercial ships in the Arctic, whilst also presenting a new environmental condition - floating ice floes. To address this emerging scenario, this paper provided an attempt to derive equations for ship resistance when operating in such floes. The equation enables the immediate prediction of icefloe resistance on a given ship and in a given ice condition, which exactly fits the need for Arctic voyage planning tools [18, 19] that can estimate fuel consumption and determine optimal shipping routes.

This work also provides insights into ship interactions with ice floes, assessing the influence of ship/ice parameters on the ice resistance. Particularly, the flexibility of the simulation approach allows easy modifications to the ship geometry, by which the influence of ship beam on the ice resistance was ascertained for the first time. Future work could investigate more advanced hull parameters, e.g. foreship shape near waterline [27], stem angle [28], bulb shape [29]; these parameters dictate the ship-ice contact surface and are important for corresponding ship design. In addition, this study is limited to a single vessel type, i.e. a container ship. The proposed approach is intended to be further applied to obtain empirical equations for other hull types. On the other hand, despite the consensus that large-scale Arctic shipping involving ice floes will occur soon, studies on the present problem are still rare and there is a scarcity of field/experimental data.

\section{ACKNOWLEDGEMENTS}

This work is part of a project that has received funding from the European Union's Horizon 2020 research and innovation programme under grant agreement No 723526 - SEDNA: Safe maritime operations under extreme conditions; the Arctic case. https://www.sedna-project.eu/.

\section{REFERENCES}

[1] Thomson, J., Ackley, S., Girard-Ardhuin, F., Ardhuin, F., Babanin, A., Boutin, G., Brozena, J., Cheng, S., Collins, C., and Doble, M., 2018, "Overview of the Arctic Sea State and Boundary Layer Physics Program," Journal of Geophysical Research: Oceans.

[2] Smith, L. C., and Stephenson, S. R., 2013, "New TransArctic Shipping Routes Navigable by Midcentury," Proceedings of the National Academy of Sciences, pp. E1191-E1195.

[3] Headland, R. K., 2019, "Transits of the Northwest Passage to End of the End of 2019 Navigation Season," Scott Polar Research Institute.

[4] 2019, "Overall NSR Voyages Statistics Distributed by Ice Class, Number of Voyages and GRT.," Northern Sea Route Information Office.

[5] Wadhams, P., 2017, A Farewell to Ice: A Report from the Arctic, Oxford University Press.

[6] Enkvist, E., 1972, On the Ice Resistance Encountered by Ships Operating in the Continuous Mode of Icebreaking.

[7] Lindquist, A., 1989, "Straightforward Method for Calculation of Ice Resistance of Ships," POAC'89.

[8] Riska, K., Wilhelmson, M., Englund, K., and Leiviskä, T., 1997, "Performance of Merchant Vessels in the Baltic," Ship Laboratory, Winter Navigation Research Board, Helsinki University of Technology, Espoo, Finland, Research Report, (52).

[9] Juva, M., and Riska, K., 2002, "On the Power Requirement in the Finnish-Swedish Ice Class Rules," Winter navigation Research Board, Res. Rpt, 53.

[10] Huang, L., Li, M., Romu, T., Dolatshah, A., and Thomas, G., 2020, "Simulation of a Ship Operating in an OpenWater Ice Channel," Ships and Offshore Structures, 0(0), pp. $1-10$.

[11] Polojärvi, A., Tuhkuri, J., and Korkalo, O., 2012, "Comparison and Analysis of Experimental and Virtual Laboratory Scale Punch through Tests," Cold Regions Science and Technology, 81, pp. 11-25.

[12] Guo, C., Xie, C., Zhang, J., Wang, S., and Zhao, D., 2018, "Experimental Investigation of the Resistance Performance and Heave and Pitch Motions of Ice-Going Container Ship Under Pack Ice Conditions," China Ocean Eng, 32(2), pp. 169-178.

[13] Luo, W.-Z., Guo, C.-Y., Wu, T.-C., and Su, Y.-M., 2018, "Experimental Research on Resistance and Motion Attitude Variation of Ship-Wave-Ice Interaction in Marginal Ice Zones," Marine Structures, 58, pp. 399-415.

[14] Kim, J.-H., Kim, Y., Kim, H.-S., and Jeong, S.-Y., 2019, "Numerical Simulation of Ice Impacts on Ship Hulls in Broken Ice Fields," Ocean Engineering, 180, pp. 162-174.

[15] Woolgar, R. C., and Colbourne, D. B., 2010, "Effects of Hull-Ice Friction Coefficient on Predictions of Pack Ice Forces for Moored Offshore Vessels," Ocean Engineering, 37(2-3), pp. 296-303.

[16] Huang, L., Li, M., Igrec, B., Cardiff, P., Stagonas, D., and Thomas, G., 2019, "Simulation of a Ship Advancing in 
Floating Ice Floes," Port and Ocean Engineering under Arctic Conditions (POAC).

[17] Huang, L., Tuhkuri, J., Igrec, B., Li, M., Stagonas, D., Toffoli, A., Cardiff, P., and Thomas, G., 2019, "Ship Resistance When Operating in Floating Ice Floes: A Combined CFD\&DEM Approach," arXiv preprint arXiv:1909.10018.

[18] Li, Z., Ringsberg, J. W., and Rita, F., 2019, "A Voyage Planning Tool for Arctic Transit of Cargo Ships," ASME 2019 38th International Conference on Ocean, Offshore and Arctic Engineering (OMAE), American Society of Mechanical Engineers, p. V008T07A015-V008T07A015.

[19] Li, Z., Ringsberg, J. W., and Rita, F., 2019, "A Voyage Planning Tool for Ships Sailing between Europe and Asia via the Arctic," International Conference on Ships and Offshore Structures.

[20] Kim, W. J., Van, S. H., and Kim, D. H., 2001, "Measurement of Flows around Modern Commercial Ship Models," Experiments in fluids, 31(5), pp. 567-578.

[21] Tuhkuri, J., and Polojärvi, A., 2018, "A Review of Discrete Element Simulation of Ice-Structure Interaction," Philosophical transactions. Series A, Mathematical, physical, and engineering sciences, 376(2129).

[22] Mucha, P., 2019, "Fully-Coupled CFD-DEM for Simulations of Ships Advancing Through Brash Ice," SNAME Maritime Convention, The Society of Naval Architects and Marine Engineers.

[23] Kitazawa, T., and Ettema, R., 1985, "Resistance to ShipHull Motion through Brash Ice," Cold Regions Science and Technology, 10(3), pp. 219-234.

[24] Alberello, A., Onorato, M., Bennetts, L., Vichi, M., Eayrs, C., MacHutchon, K., and Toffoli, A., 2019, "Brief Communication: Pancake Ice Floe Size Distribution during the Winter Expansion of the Antarctic Marginal Ice Zone," The Cryosphere, 13(1), pp. 41-48.

[25] ITTC, 2008, "1978 ITTC Performance Prediction Method," Recommended Procedures and Guidelines.

[26] ITTC, 2017, "General Guidance and Introduction to Ice Model Test," ITTC Report.

[27] Kim, M.-C., Lee, W.-J., and Shin, Y.-J., 2014, "Comparative Study on the Resistance Performance of an Icebreaking Cargo Vessel According to the Variation of Waterline Angles in Pack Ice Conditions," International Journal of Naval Architecture and Ocean Engineering, 6(4), pp. 876-893.

[28] Noblesse, F., Delhommeau, G., Guilbaud, M., and Yang, C., 2008, "The Rise of Water at a Ship Stem," Journal of Ship Research, 52(2), pp. 89-101.

[29] Grech La Rosa, A., Thomas, G., Muk-Pavic, E., and Dinham-Peren, T., 2015, "Bulbous Bows for Energy Efficient Ships: A Novel Approach,” RINA.

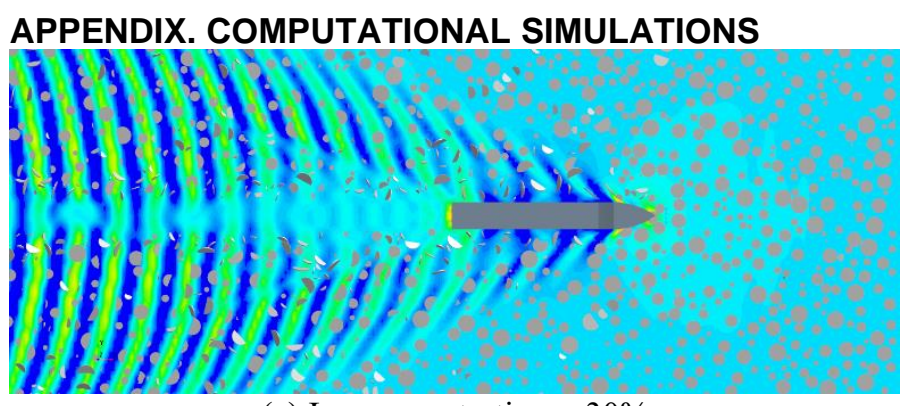

(a) Ice concentration $=30 \%$

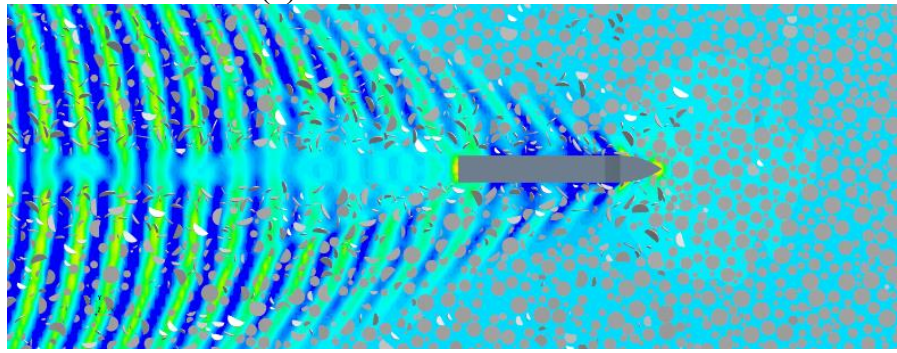

(b) Ice concentration $=50 \%$

FIGURE I: Simulation view of a ship advancing in floating ice floes, with different ice concentrations applied.

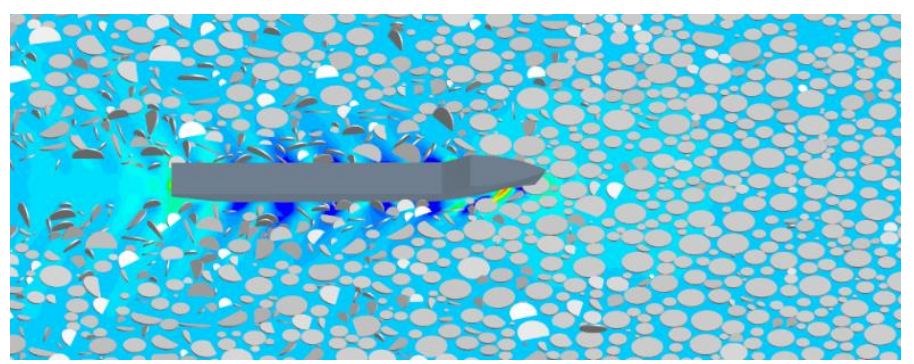

(a) Floe diameters same as in [12]

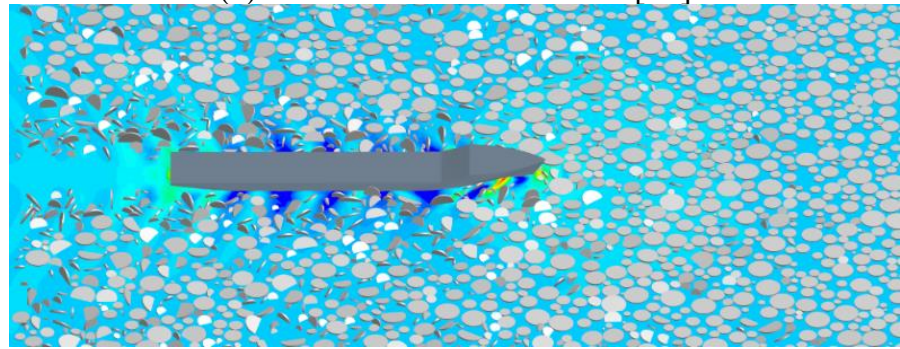

(b) Floe diameters are $60 \%$ of those in [12]

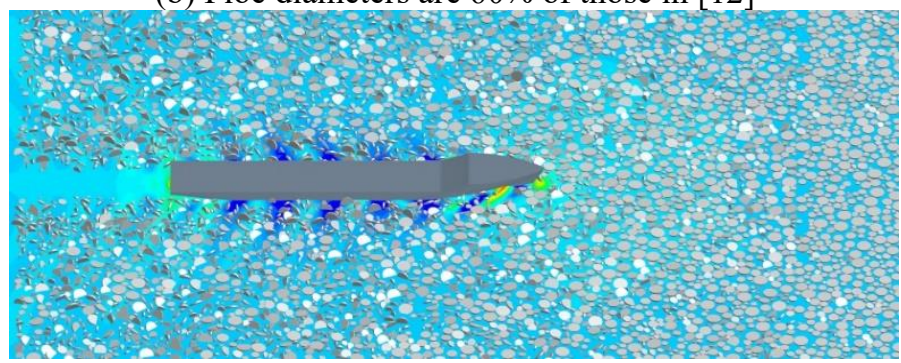

(c) Floe diameters are $20 \%$ of those in [12]

FIGURE II: Simulation view of a ship advancing in floating ice floes, with different floe sizes applied. 